\title{
Эффективность применения средств физической реабилитации в технологии коррекции нарушений осанки танцоров высокой квалификации
}

\author{
УДК: 796.012.265:793.33+616.711-085 \\ Е. Б. Лазарева, Т. А. Рожкова, Д. Н. Бойко \\ Национальный университет физического воспитания и спорта Украины, Киев, \\ Украина
}

\begin{abstract}
Резюме. Мета. Розробка технології корекції порушень постави, спрямованої на поліпшення стану опорно-рухового апарату спортсменів високої кваліфікації, які спеціалізуються у спортивних танцях. Для оцінки ефективності технології корекції порушень постави в динаміці оцінювалися показники стабілографії танцюристів високої кваліфікації.

Методи. Аналіз спеціальної науково-методичної літератури; педагогічні та біомеханічні методи. Результати. Визначено особливості морфофункціонального стану спортсменів, котрі зумовлюють спрямованість процесу корекції, зміст процедур лікувальної гімнастики, партерної гімнастики, занять коригуючими вправами, методику масажу, гідрокінезитерапії 3 елементами лікувального плавання, елементів функціонального тренінгу та Пілатеса, спрямованих на поліпшення стану опорно-рухового апарату спортсменів високої кваліфікації. Після застосування запропонованої технології було виявлено достовірні позитивні зміни в показниках стабілографії.

Висновки. Експериментальна перевірка розробленої технології корекції порушень постави спортсменів високої кваліфікації показала свою ефективність, яка проявляється у зміні показників часу домінанти навантаження у балансувальному стабілографічному тесті.

Ключові слова: фізична реабілітація, корекція, порушення постави, опорно-руховий апарат, спортивні танці, стабілографія.
\end{abstract}

\begin{abstract}
Aim. The publication focuses on developing the technology for posture correction, aimed at improving the condition of the locomotor system in elite athletes specialized in sports dancing. For evaluation the effectiveness of posture correction technology in dynamics stabilography indicators were evaluated in highly skilled dancers.

Methods. Analysis of special scientific-methodical literature; pedagogical and biomechanical methods. Results. There were determined the peculiarities of the morphofunctional status of athletes, which determine the focus of posture correction process, content of the procedures of therapeutic gymnastics, corrective exercise sessions, technique of massage, hydrokinesiotherapy with the elements of therapeutic swimming, elements of functional training and Pilates, that are aimed at improving the condition of the locomotor system in elite athletes. Applying the proposed technology resulted in significant positive changes in the indicators of stabilography. Conclusions. Experimental validation of the developed technology of posture correction of highly skilled athletes proved its efficiency, which is manifested in: time change dominant of load in balancing stabilographic test.

Key words: physical rehabilitation, correction, postural defects, locomotor system, sport dancing, stabilography.
\end{abstract}

\begin{abstract}
Постановка проблемы. Анализ последних исследований и публикаций. Спортивные танцы малоизучены с точки зрения науки, по сравнению с большинством других стремительно развивающихся видов спорта. Основное внимание специалистов уделено технике выполнения единичных движений в спортивных танцах [1], разным видам подготовленности танцоров и их совершенствования [4], биомеханике танцевальных движений [8].
\end{abstract}

Спортивные танцы - парный, ацикличный, сложнокоординационный вид спорта, требующий от спортсменов выполнения большого количества разнообразных технических действий. Стремительное развитие данного вида спорта, расширение соревновательного календаря, форсирование спортивной подготовки, приводит к тому, что организм танцора подвергается чрезмерным нагрузкам на разные его системы. 
В процессе учебно-тренировочных занятий и соревнований, спортсмены испытывают большие по объему и интенсивности, часто асимметричные, статодинамические нагрузки. Во время соревновательной и тренировочной деятельности организм танцора подвергается растяжениям, сжимающим и скручивающим воздействиям специфических фризических упражнений, что может отрицательно сказываться на здоровье спортсмена, приводя к нарушениям и повреждениям со стороны опорно-двигательного аппарата (ОДА), первопричиной которых зачастую являются нарушения осанки.

Одной из основных причин нарушений осанки в спорте является относительная слабость некоторых отделов ОДА, которая проявляется при больших тренировочных загрузках [9].

Рассматривая процесс многолетней подготовки в спортивных танцах, можно определить, что именно на этапе максимальной реализации индивидуальных возможностей, происходит узкая специализация и танцоры, которые переходят на исполнение исключительно стандартной программы спортивных танцев, испытывают асимметричное воздействие на ОДА. Кроме того, на этом этапе существенно возрастает тренировочная и соревновательная нагрузка. Количество тренировок - ежедневно 3-6 ч, соревнований 25-30 в год. Спортсмены зачастую пренебрегают общей фризической подготовкой, а профилактические мероприятия, необходимые при асимметричных нагрузках на ОДА, вовсе отсутствуют.

Спортивные танцы как вид спорта нельзя отнести к какому-то одному виду нагрузки. Однако, если рассматривать танцевальные программы отдельно, то можно определить, что латиноамериканская программа предусматривает симметричную наргузку, программа десяти танцев смешанную, что не оказывает такого негативного влияния на ОДА, как стандартная программа, предусматривающая асимметричную загрузку.

Позиция танцевальной стойки в стандартной программе, которую спортсмены сохраняют на протяжении исполнения всего танца, имеет четкую асимметричную особенность построения тел партнеров. В основной позиции спортсмены стоят лицом друг к другу, но партнерша находится немного правее партнера, слегка отклонив корпус назад. Правой рукой партнер держит партнершу за лопатку (пальцы руки собраны, локоть согнут и поднят выше кисти), а ее левая рука лежит на правой руке партнера. Левая рука партнера и правая рука партнерши соединены, согнутые локти образуют острый угол, кисти рук немного выше плеча. Корпус партнера слегка развернут правым плечом в направлении движения. Мышцы тел спортсменов растянуты и их тонус повышен. Традиционный характерный облик партнерши создается вытягиванием ее тела вверх от голеностопа в форме дугообразной кривой, причем бедра и пояс являются сознательными точками контакта с центральной линией партнера. Для обеспечения должной результативности двигательных действий необходимо выполнение рабочих поз и специфических осанок, используемых спортсменами в составе техники упражнений. Деятельность спортсменов базируется на искусственных формах движений, следовательно, создает свои условия для формирования осанки, целесообразной для качественного выполнения технических элементов. Рабочая осанка определяется пространственно-координационной системой конкретного вида двигательной активности. Так, в спортивных танцах она определяется трудностью постановки правильного положения туловища, головы, рук, ног, которая находится в прямой зависимости от площади опоры, сложности координации танцевально-хореографических движений, изменения положения общего центра тяжести тела [2].

В спортивных танцах танцевальная осанка подразумевает выработанную в соответствии с профессиональными требованиями манеру держать свое тело в статике и динамике в пространственных и временных условиях. Она характеризуется гармонией пропорций, форм и линий тела, пластичностью и художественной выразительностью движений, поз, способствующих созданию характера исполняемого танца. Сорормированная танцевальная осанка обеспечивает устойчивость тела, достигаемую путем координированной работы мышц и всех частей тела.

В наше время специалистами уделено достаточное внимание особенностям статодинамических показателей у спортсменов зимних видов спорта [6], особенностям пространственного положения туловища, таза и стоп у спортсменовмужчин высокой квалификации [7], динамике стабилографических показателей юных пловцов [5]. Однако данные, касающиеся спортсменов, специализирующихся в спортивных танцах, отсутствуют.

Все вышесказанное выдвигает на первый план вопросы изучения особенностей показателей стабилографии танцоров, а так же разработки и внедрения профрилактических и реабилитационных мероприятий, направленных на коррекцию патобиомеханических нарушений и закрепление оптимального двигательного стереотипа, способствующего поддержанию высокого уровня спортивной работоспособности. 
Цель исследования - проанализировать динамику показателей стабилографического исследования танцоров высокой квалификации под влиянием технологии коррекции нарушений осанки.

Методы и организация исследования. Для решения поставленной цели нами применялись следующие методы исследования: анализ специальной научно-методической литературы; педагогические; биомеханические и методы математической статистики.

Метод стабилографрии применялся для оценки вертикальной устойчивости тела спортсмена, которая является важным индикатором функционального состояния ОДА и позволяет получить количественные и качественные показатели устойчивости тела в пространстве. Для оценки двигательных функций, проприоцептивной и вестибулярной системы танцоров высокой квалификации использовалась стабилографическая платорорма Gamma (AC International, Польша).

Для исследования динамических параметров ходьбы исследуемым было предложено выполнение степ-теста на месте. Регистрации подлежали параметры: нагрузка на правую и левую нижние конечности во время ходьбы (максимум распределения нагрузки, \%), длительность: шага, фазы переноса и стояния. Для оценки динамики постурального контроля, спортсменам предлагалось выполнение балансировочного теста. В процессе выполнения теста измерялось распределение веса и диспропорции между сторонами/конечностями, показатель - время доминанты нагрузки (\%).

Педагогический эксперимент проводился в три этапа: первые два -констатирующие, между ними был год педагогического наблюдения, во время которого спортсмены продолжали тренировочную и соревновательную деятельность без внедрения каких-либо средств, влияющих на состояние опорно-двигательного аппарата, и формирующего, в конце которого проводились заключительные исследования.

Материалы работы были получены при проведении исследований на базе клуба спортивного танца «Супаданс», г. Киев; Института травматологии и ортопедии АМН Украины, г. Киев. В исследовании приняли участие 32 спортсмена, специализирующихся в спортивных танцах, имеющие спортивную квалификацию МС, МСМК. Тестирование проводилось после дня отдыха при стандартизованном режиме питания и питьевого режима. Спортсмены были осведомлены о содержании тестов и дали согласие на их проведение.

Результаты исследования и их обсуждение. Результаты стабилографического исследования при выполнении шагового теста на месте у танцоров высокой квалификации с нарушениями осанки представлены в таблице 1.

При анализе показателей шагового теста средние значения показателя максимального веса правой ноги составили 76,5 $\pm 13,47$ кг ( $\mathrm{V}=17,6 \%)$ у спортсменов и 58,4 $\pm 8,59$ кг ( $V=14,7 \%)$ у спортсменок. Средние значения показателя максимального веса левой ноги составили $71,7 \pm 10,10$ кг $(\mathrm{V}=14,1 \%)$ у спортсменов и $61,3 \pm 9,87$ кг $(\mathrm{V}=16,1 \%)$ у спортсменок. Следует отметить тот фракт, что при выполнении шагового теста, доминанта среднего значения показателя максимального веса правой ноги отмечалась у спортсменов-мужчин, что связано с большей нагрузкой при выполнении танцевальных элементов на правую ногу, а также тем, что для успешного взаимодействия в паре, танцоры имеют плотный контакт друг с другом в правом бедре и правая стопа у спортсменов является опорной чаще, чем левая. При построении нейтральной танцевальной позиции, $90 \%$ веса партнера находится на правой ноге, в то время как у спортсменок аналогичная ситуация происходит с левой ногой.

В таблице 2 представлены результаты стабилографического исследования при выполнении балансировочного теста.

Время доминанты нагрузки для левой ноги составило у спортсменов 39,9 $\pm 5,14 \%$ $(\mathrm{V}=12,8 \%)$ и у спортсменок $-63,6 \pm 8,68 \%$ $(\mathrm{V}=13,6 \%)$, время доминанты нагрузки для правой ноги составило $60,1 \pm 5,48 \%$ (V $=$

ТАБЛИЦА 1 - Показатели стабилографии при выполнении шагового теста на месте у танцоров высокой квалификации с нарушениями осанки, $\mathrm{n}=32$

\begin{tabular}{|c|c|c|c|c|c|c|c|}
\hline Исследуемый показатель & Контингент & $\overline{\mathbf{x}}$ & $\mathbf{S}$ & Me & $25 \%$ & $75 \%$ & $\mathrm{~V}, \%$ \\
\hline \multirow{2}{*}{$\begin{array}{l}\text { Среднее значение показателя мак- } \\
\text { симальной нагрузки правой ноги, кг }\end{array}$} & Спортсмены, n = 19 & 76,5 & 13,47 & 75,5 & 67,7 & 81,3 & 17,6 \\
\hline & Спортсменки, n = 13 & 58,4 & 8,59 & 55,9 & 54,5 & 57,1 & 14,7 \\
\hline \multirow{2}{*}{$\begin{array}{l}\text { Среднее значение показателя мак- } \\
\text { симальной нагрузки левой ноги, кг }\end{array}$} & Спортсмены, n = 19 & 71,7 & 10,10 & 73,3 & 63,3 & 77,4 & 14,1 \\
\hline & Спортсменки, n = 13 & 61,3 & 9,87 & 58,7 & 57,4 & 59,6 & 16,1 \\
\hline
\end{tabular}


ТАБЛИЦА 2 - Показатели стабилографии при выполнении балансировочного теста у танцоров высокой квалификации с нарушениями осанки, $\mathrm{n}=32$

\begin{tabular}{|l|l|c|c|l|}
\hline \multicolumn{1}{|c|}{$\begin{array}{c}\text { Исследуемый } \\
\text { показатель }\end{array}$} & \multicolumn{1}{|c|}{ Контингент } & $\overline{\mathbf{x}}$ & $\mathbf{s}$ & $\mathbf{v}, \%$ \\
\hline $\begin{array}{l}\text { Время доминанты } \\
\text { нагрузки правой } \\
\text { ноги, \% }\end{array}$ & Спортсмены, $\mathrm{n}=19$ & 60,1 & 5,48 & 9,1 \\
\cline { 2 - 5 } & Спортсменки, $\mathrm{n}=13$ & 36,4 & 5,68 & 13,8 \\
\hline $\begin{array}{l}\text { Время доминанты } \\
\text { нагрузки левой } \\
\text { ноги, \% }\end{array}$ & Спортсмены, $\mathrm{n}=19$ & 40,2 & 5,14 & 12,8 \\
\cline { 2 - 5 } & Спортсменки, $\mathrm{n}=13$ & 63,6 & 8,68 & 13,6 \\
\hline
\end{tabular}

$=9,1 \%)$ и 36,4 $\pm 5,68 \%(\mathrm{~V}=13,8 \%)$ соответственно.

Данные, полученные при анализе показателей балансировочного теста, подтверждают то, что вес танцоров распределен неравномерно, что обусловлено техническими требованиями данного вида спорта. Основной причиной неравномерного распределения веса является то, что танцоры имеют опорную ногу, а также стоят в определенной позиции друг с другом, для сохранения которой большая часть веса во время танца находится на одной из ног. При построении нейтральной танцевальной позиции как партнер, так и партнерша $90 \%$ веса распределяют на одну из ног, а именно - спортсменки на левую, а спортсмены на правую ногу. Можно предположить, что это является основной причиной неравномерного распределения веса при выполнении данного теста.

Таким образом, полученные результаты свидетельствуют о необходимости разработки комплексной технологии, которая способствует коррекции нарушений осанки и закреплению оптимального двигательного стереотипа спортсменов.

Структура технологии коррекции нарушений осанки спортсменов высокой квалификации, специализирующихся в спортивных танцах, с применением средств фризической реабилитации представлена на рисунке 1.

Применяемые средства были разделены на базовый и вариативный компоненты с учетом принципов фризической реабилитации, принципов педагогического взаимодействия, локализации и степени выявленных нарушений, режима тренировок и отдыха спортсменов, а также особенностей периодов годичного макроцикла спортивной подготовки. Методы проведения реабилитационных мероприятий: малогрупповой и индивидуальный.

Адаптационный период технологии отвечал переходному периоду годичного макроцикла спортивной подготовки. Целью переходного периода является восстановление фризичес- кого состояния спортсменов после интенсивной соревновательной деятельности. Продолжительность периода - 60 дней. В базовом компоненте технологии использовали: лечебную гимнастику с элементами Пилатеса и гидрокинезитерапию. В вариативном - лечебный массаж и элементы лечебного плавания. Также спортсменам были даны рекомендации по поводу использования ортопедических стелек в повседневной жизни. Параметры дозировки нагрузки ЛГ: длительность процедуры ЛГ - 60 мин; И.п. - стоя, сидя, лежа на спине; количество повторения фиизических упражнений - 8-10 раз; темп выполнения - медленный и средний; амплитуда - неполная, средняя.

Тренировочно-корригирующий период технологии соответствовал общеподготовительному этапу подготовительного периода спортивной подготовки, который характеризуется средними нагрузками и пониженной интенсивностью тренировочной деятельности. Занятия корригирующей гимнастики проводились 3 раза в неделю через полтора часа после спортивной тренировки. Параметры дозировки нагрузки корригирующей гимнастики: длительность процедуры - 45-60 мин. И.п. - стоя у гимнастической стенки, лежа на животе, лежа на спине, на животе, кисте - коленное положение. Количество повторений фризических упражнений - от 4-6 до 8-10 раз. Темп выполнения - медленный и средний. Амплитуда - неполная, средняя.

Упражнения партерной гимнастики имели симметричный характер и были направлены на укрепление глубоких мышц спины, мышц брюшного пресса, растяжение мышц-сгибателей и укрепление мышц-разгибателей, растягивание и укрепление связок. Темп выполнения - медленный, средний и высокий; амплитуда - максимальная.

Стабилизационный период технологии отвечал специально-подготовительному этапу подготовительного периода спортивной подготовки. Так как в это время значительно возрастает интенсивность и объем тренировок, особое внимание было необходимо уделить закреплению достигнутого результата коррекции. Продолжительность периода - 80 дней. Лечебная гимнастика с элементами фрункционального тренинга проводилась 3 раза в неделю; гидрокинезитерапия с элементами аквафитнеса и партерная гимнастика - 2 раза в неделю.

Поддерживающий период технологии отвечал соревновательному периоду спортивной подготовки. Спортсмены высокой квалификации имеют плотный графрик международных 
Технология коррекции осанки спортсменов, высокой квалификации, специализирующихся в спортивных танцах (в зависимости от периода годичного макроцикла)

\begin{tabular}{|c|c|c|c|}
\hline 1 & 1 & 1 & 1 \\
\hline $\begin{array}{c}\text { Адаптационный } \\
\text { период }\end{array}$ & $\begin{array}{c}\text { Тренировочно- } \\
\text { корригирующий период }\end{array}$ & $\begin{array}{c}\text { Стабилизационный } \\
\text { период }\end{array}$ & $\begin{array}{c}\text { Поддерживающий } \\
\text { период }\end{array}$ \\
\hline
\end{tabular}

\begin{tabular}{|c|c|c|c|}
\hline \multicolumn{4}{|c|}{ Годичный цикл спортивной подготовки } \\
\hline \multicolumn{4}{|c|}{1} \\
\hline \multicolumn{4}{|c|}{ Задачи технологии } \\
\hline 1 & 1 & 1 & 1 \\
\hline $\begin{array}{l}\text { - Снижение болевого } \\
\text { синдрома. } \\
\text { - Гравитационная разгрузка } \\
\text { позвоночника после } \\
\text { физических нагрузок. } \\
\text { - Расслабление } \\
\text { спазмированных мышц } \\
\text { в зоне поражения. } \\
\text { - Стимуляция крово- } \\
\text { и лимфотока в зоне } \\
\text { поражения }\end{array}$ & $\begin{array}{l}\text { - Выработка навыка } \\
\text { правильной осанки. } \\
\text { - Коррекция выявленных } \\
\text { нарушений осанки. } \\
\text { • Подбор ортопедических } \\
\text { мероприятий для } \\
\text { коррекции } \\
\text { плоскостопия }\end{array}$ & $\begin{array}{l}\text { - Стабилизация } \\
\text { позвоночника, } \\
\text { укрепление достигнутой } \\
\text { коррекции. } \\
\text { - Укрепление мышечных } \\
\text { групп нижних конечностей } \\
\text { и туловища. } \\
\text { - Укрепление мышц } \\
\text { свода стопы }\end{array}$ & $\begin{array}{l}\text { - Устранение болевого } \\
\text { синдрома. } \\
\text { - Разгрузка позвоночника } \\
\text { после физических } \\
\text { перенапряжений. } \\
\text { - Ускорение восстановления } \\
\text { мышечных групп, } \\
\text { подвергающихся } \\
\text { максимальной нагрузке }\end{array}$ \\
\hline \pm & $\perp$ & \pm & 1 \\
\hline \multicolumn{4}{|c|}{ Компоненты технологии } \\
\hline \multicolumn{2}{|c|}{ Базовый компонент } & \multicolumn{2}{|c|}{ Вариативный компонент } \\
\hline
\end{tabular}

\begin{tabular}{|c|c|}
\hline $\begin{array}{l}\text { Мероприятия, направленные на: } \\
\text { - улучшение функционального состояния } \\
\text { опорно-двигательного аппарата; } \\
\text { - улучшение опорно-рессорных свойств стопы; } \\
\text { - формирование правильного двигательного стереотипа; } \\
\text { - укрепление мышечного корсета }\end{array}$ & $\begin{array}{l}\text { Мероприятия, направленные на коррекцию } \\
\text { патобиомеханических нарушений во фронтальной } \\
\text { и сагиттальной плоскостях }\end{array}$ \\
\hline $\begin{array}{l}\text { Для спортсменов с нарушениями осанки } \\
\text { во фронтальной плоскости: } \\
\text { выравнивание баланса правой и левой половины тела } \\
\text { с помощью растяжения спазмированных мышц } \\
\text { с одновременным укреплением перерастянутых мышц }\end{array}$ & Коррекция кругловогнутой осанки у мужчин \\
\hline
\end{tabular}

Контроль и оценка эффективности внедрения технологии коррекции осанки

Рисунок 1 - Структура технологии коррекции нарушений осанки в зависимости от периода годичного макроцикла спортивной подготовки

соревнований, что препятствует полноценному восстановлению организма. Поэтому спортсменам рекомендовалась сауна для ускорения восстановительных процессов после соревнований.

Годовой период педагогического наблюдения позволил выявить увеличение асимметрии распределения нагрузки на нижние конечности. При проведении повторного обследования, на втором этапе педагогического эксперимента, были зафриксированы изменения показателей при выполнении шагового теста на месте, что связано с нарушением осанки во фрронтальной плоскости (табл. 3). 
ТАБЛИЦА 3 - Динамика показателей стабилографии при выполнении шагового теста у танцоров высокой квалификации с нарушениями осанки, $\mathrm{n}=32$

\begin{tabular}{|c|c|c|c|c|c|c|c|c|c|c|}
\hline \multirow{2}{*}{ Исследуемый показатель } & \multirow{2}{*}{ Контингент } & \multicolumn{2}{|c|}{ Первый этап } & \multicolumn{2}{|c|}{ Второй этап } & \multirow{2}{*}{$\begin{array}{c}\text { Р между } \\
\text { первым } \\
\text { и вторым } \\
\text { этапами }\end{array}$} & \multicolumn{2}{|c|}{ Третий этап } & \multicolumn{2}{|c|}{$\begin{array}{c}\text { P } \\
\text { между этапами }\end{array}$} \\
\hline & & $\overline{\mathbf{x}}$ & $\mathbf{s}$ & $\overline{\mathbf{x}}$ & $\mathbf{s}$ & & $\overline{\mathbf{x}}$ & $\mathbf{s}$ & $\begin{array}{c}\text { первым и } \\
\text { третьим }\end{array}$ & $\begin{array}{l}\text { вторым и } \\
\text { третьим }\end{array}$ \\
\hline \multirow{2}{*}{$\begin{array}{l}\text { Среднее значение } \\
\text { показателя максимальной } \\
\text { нагрузки правой ноги, кг }\end{array}$} & Спортсмены, n = 19 & 76,5 & 13,47 & 78,9 & 6,17 & $>0,05$ & 75,2 & 5,14 & $>0,05$ & $<0,05$ \\
\hline & Спортсменки, $\mathrm{n}=13$ & 58,4 & 8,59 & 57,8 & 4,12 & $>0,05$ & 59,9 & 6,23 & $>0,05$ & $>0,05$ \\
\hline \multirow{2}{*}{$\begin{array}{l}\text { Среднее значение по- } \\
\text { казателя максимальной } \\
\text { нагрузки левой ноги, кг }\end{array}$} & Спортсмены, n = 19 & 71,7 & 10,10 & 69,3 & 8,11 & $>0,05$ & 73,6 & 6,93 & $>0,05$ & $<0,05$ \\
\hline & Спортсменки, $\mathrm{n}=13$ & 61,3 & 9,87 & 63,7 & 6,28 & $>0,05$ & 61,1 & 5,49 & $>0,05$ & $<0,05$ \\
\hline
\end{tabular}

ТАБЛИЦА 4 - Динамика показателей стабилографии при выполнении балансировочного теста у танцоров высокой квалификации с нарушениями осанки, $\mathrm{n}=32$

\begin{tabular}{|c|c|c|c|c|c|c|c|c|c|c|}
\hline \multirow{2}{*}{$\begin{array}{c}\text { Исследуемый } \\
\text { показатель }\end{array}$} & \multirow{2}{*}{ Контингент } & \multicolumn{2}{|c|}{ Первый этап } & \multicolumn{2}{|c|}{ Второй этап } & \multirow{2}{*}{$\begin{array}{c}\text { Р между } \\
\text { первым и вторым } \\
\text { этапами }\end{array}$} & \multicolumn{2}{|c|}{ Третий этап } & \multicolumn{2}{|c|}{$\begin{array}{c}\text { P } \\
\text { между этапами }\end{array}$} \\
\hline & & $\overline{\mathbf{x}}$ & $s$ & $\overline{\mathbf{x}}$ & $s$ & & $\overline{\mathbf{x}}$ & $\mathbf{s}$ & $\begin{array}{l}\text { первым и } \\
\text { третьим }\end{array}$ & $\begin{array}{c}\text { вторым и } \\
\text { третьим }\end{array}$ \\
\hline \multirow{2}{*}{$\begin{array}{l}\text { Время доминанты } \\
\text { нагрузки правой } \\
\text { ноги, \% }\end{array}$} & Спортсмены, n = 19 & 60,1 & 5,48 & 63,6 & 5,7 & $>0,05$ & 53,5 & 4,05 & $<0,01$ & $<0,01$ \\
\hline & Спортсменки, $\mathrm{n}=13$ & 36,4 & 5,68 & 35,9 & 7,9 & $>0,05$ & 48,3 & 7,58 & $<0,05$ & $<0,05$ \\
\hline \multirow{2}{*}{$\begin{array}{l}\text { Время доминанты } \\
\text { нагрузки левой } \\
\text { ноги, \% }\end{array}$} & Спортсмены, n = 19 & 40,2 & 5,14 & 36,4 & 5,92 & $>0,05$ & 46,5 & 4,05 & $<0,01$ & $<0,01$ \\
\hline & Спортсменки, n = 13 & 63,6 & 8,68 & 64,1 & 7,1 & $>0,05$ & 51,7 & 7,58 & $<0,05$ & $<0,05$ \\
\hline
\end{tabular}

Так, у спортсменов на втором этапе педагогического эксперимента значение показателя максимального веса правой ноги составило $78,9 \pm 6,17$ кг у спортсменов и 57,8 $\pm 4,12$ кг у спортсменок, а среднее значение показателя максимального веса левой ноги - 69,3 $\pm 8,11$ кг и 63,7 \pm 6,28 кг соответственно при р $>0,05$.

На третьем этапе педагогического эксперимента, были получены достоверные показатели, характеризующие состояние опорно-двигательного аппарата спортсменов, подтверждающие эфффективность применения разработанной технологии.

После применения разработанной технологии коррекции нарушений осанки изменились показатели на обеих ногах как у спортсменов, так и у спортсменок в сторону улучшения. Так, среднее значение показателя максимальной нагрузки правой ноги составило 75,2 \pm 5,14 кг у спортсменов, а 59,9 $\pm 6,23$ кг у спортсменок, а среднее значение показателя максимальной нагрузки левой ноги составило 73,6 \pm 6,93 кг и 61,1 $\pm 5,49$ кг соответственно при р > 0,05, что указывает на то, что разработанная технология коррекции нарушений осанки спортсменов высокой квалификации, специализирующихся в спортивных танцах, положительно повлияла на их ОДА, так как разница между средними значениями показателя максимальной нагрузки левой и правой ноги уменьшилась.

При проведении повторного обследования на втором этапе педагогического эксперимента нами было зафиксировано перераспределение времени доминанты нагрузки, что связано с нарушением осанки во фронтальной плоскости (табл. 4).

Так, у спортсменов на втором этапе педагогического эксперимента данный показатель для правой ноги составил $63,6 \pm 5,7 \%$, для левой ноги $36,4 \pm 5,92 \%$, что указывает на значительный перенос нагрузки на правую ногу. У спортсменок этот же показатель правой ноги на втором этапе педагогического эксперимента был равен 35,9 \pm $\pm 7,9 \%$, для левой ноги $-64,1 \pm 7,1 \%$, что указывает на перераспределение нагрузки.

Под влиянием разработанной технологии коррекции изменились показатели на обеих ногах как у спортсменов, так и у спортсменок. Так, показатель доминанты нагрузки правой ноги у спортсменов составил 53,5 $\pm 4,05 \%$, левой ноги $-46,5 \pm 4,05 \%$ при $p<0,01$. Этот же показатель на левой ноге у спортсменок составил $51,7 \pm 7,58 \%$, показатель правой $48,3 \pm 7,58 \%$ при р > 0,05.

Выводы. В результате предварительных исследований нами были зафиксированы негативные изменения ОДА спортсменов, которые 
связаны с их профрессиональной деятельностью. Неравномерное распределение времени доминанты нагрузки для левой ноги в балансировочном стабилографрическом тесте у спортсменов ( $\overline{\mathrm{x}} \pm \mathrm{S})$ $39,9 \pm 5,14$ и 63,6 \pm 8,68 \% у спортсменок, а для правой ноги $-60,1 \pm 5,48$ и 36,4 $\pm 5,68 \%$ соответственно.

Годовой период педагогического наблюдения позволил выявить увеличение асимметрии распределения нагрузки на нижние конечности. Увеличилось время доминанты нагрузки в балансировочном тесте на правой ноге у спортсменов до ( $\bar{x} \pm S) 63,6 \pm 5,7 \%$, и левой ноге у спортсменок до $64,1 \pm 7,1 \%$.

Разработанная технология коррекции нарушений осанки танцоров высокой квалификации состоит из четырех периодов: адаптационного, тренировочно-корригирующего, стабилизационного и поддерживающего. Внедрение технологии проводилось без вмешательства в тренировочную деятельность спортсменов и с учетом особенностей спортивной подготовки на каждом из этапов

\section{Литература}

1. Вакуленко М. А. Техника в спортивных танцах и ее проблемы / М. А. Вакуленко // Материалы IV науч.-метод. конф. по пробл. спорт. танцев (Москва, 22-26 феевр. 2000 г.) / РГАФК. - М., 2000. - С. 54-56.

2. КареВа И. В. Формирование рабочей осанки у юных спортсменов-танцоров на этапе начальной подготовки с использованием статодинамических упражнений : автореср. дис. на соискание учен. степени канд. пед. наук : спец. 13.00.04 / Карева И. В. - Волгоград, 2013. - 25 с.

3. Кашуба В. А. Биомеханика осанки / В. А. Кашуба. - К. : Олимп. лит., 2003. - 279 с.

4. КоВаленко А. А. Использование вращательных элементов в соревновательных композициях спортсменовтанцоров / А. А. Коваленко // Спорт. танцы. - 2001. № 5 (21). - C. 19-32.

5. Колісник B. Динаміка стабілометричних показників у юних плавців 7-9 років з нефіксованими порушеннями опорно-рухового апарату / В. Колісник, В. Клапчук, Т. Шитіков / / Спорт. вісн. Придніпров'я. - 2009. - № 3. C. $168-171$.

6. Котенко К. В. Особенности статодинамических показателей у спортсменов зимних видов спорта / К. В. Котенко, Н. Б. Корчажкина, А. В. Епифранов и др. // Сарат. науч.-мед. журн. - 2014. - № 4. - С. 899-901.

7. КочеткоВа Н. И. Особенности пространственного положения туловища, таза и стоп у высококвалифрицированных спортсменов мужчин различных видов спорта / Н. И. Кочеткова, Т. Ф. Абрамова, Т. М. Никитина, В. А. Красников. // Вестн. спорт. науки. - 2013. - № 5. - С. 58-65.

8. Кошелев С. Н. Биомеханика спортивных танцев / С. Н. Кошелев. - М.: Мир, 2006. - 140 с.

9. Рожкова T. Вплив занять спортивними танцями на опорно-руховий апарат спортсменів / Т. Рожкова // Спорт. вісн. Придніпров'я. - 2013. - № 3. - С. 82-86. годичного макроцикла. Использовались лечебная гимнастика, партерная гимнастика, занятия корригирующими упражнениями, массаж, гидрокинезитерапия с элементами лечебного плавания, элементы фрункционального тренинга и Пилатеса, которые распределены на базовый и вариативный компоненты с учетом принципов физической реабилитации, принципов педагогического взаимодействия, локализации и степени выявленных нарушений, режима тренировок и отдыха спортсменов.

Экспериментальная проверка разработанной технологии коррекции нарушений осанки спортсменов высокой квалификации показала свою эффрективность, которая проявляется в изменении показателей времени доминанты нагрузки в балансировочном стабилографическом тесте: показатель доминанты правой ноги у спортсменов составил 53,5 \pm 4,05 \%, левой ноги $46,5 \pm 4,05 \%$ ( $<<0,01)$. Этот же показатель левой ноги у спортсменок составил 51,7 \pm 7,58 \%, правой $-48,3 \pm 7,58 \%$ ( $<<0,05)$.

\section{References}

1. Vakulenko M. A. Technique in sports dance and its problems / M. A. Vakulenko // Proceedings of the IV scientificmethod.conf. on the problems of sports dancing (Moscow, 2226 February 2000) / RGAFK. - Moscow, 2000. - P. 54-56.

2. Kareva I. V. Forming a working posture in young dancers athletes at the stage of initial preparation with the use of staticdynamic exercises: author's abstract for Ph.D. in Pedagogics: spec. 13.00.04 / Kareva I. V. - Volgograd, 2013. - 25 p.

3. Kashuba V. A. Biomechanics of posture / V. A. Kashuba. - Kiev: Olimpiyskaya literatura. 2003. -279 p.

4. Kovalenko $A$. A. Using the rotational elements in competitive athletes compositions dancers / A. A. Kovalenko // Sport. tantsy. - N 5 (21). - Moscow, RGAFK, 2001. P. $9-32$.

5. Kolisnik V. Dynamics of stabilographic performance in young swimmers of 7-9 years with nonfixed disorders of the musculoskeletal system / V. Kolesnikov, V. Klapchuk, T. Shitikov. // Sportyvnyi visnyk prydniprovia. - 2009. - N 3. P. $168-171$.

6. Kotenko K. V. Features of static-dynamic performance in athletes of winter sports / K. V. Kotenko, N. B. Korchazhkina A. V. Epifanov et al. // Saratov J. of Medical Science. - 2014. - N 4. - P. 899-901.

7. Kochetkova N. I. Features of the spatial position of the torso, pelvis and feet in elite athletes of different sports events / N. I. Kochetkova, T. F. Abramova, T. M. Nikitina, V. A. Krasnikov // Vestnik sportivnoy nauki. - 2013. N 5. - P. 58-65.

8. Koshelev S. N. Dance Sport Biomechanics / S. Koshelev. - Moscow: Mir, 2006. - $140 \mathrm{p}$.

9. T. Rozhkova. Influence of employment by sports dances on the musculoskeletal system of athletes / T. Rozhkova // Sportyvnyi visnyk prydniprovia. - 2013. - N 3. - P. 8286.

Поступила 03.12.2015 